residents performing ECT and will eventually practise ECT by themselves.

In terms of management skills, they must take the role of chief resident at least for some period in the last year of training. They will also be involved in ongoing qualityimprovement activities which are related to the hospital accreditation process.

\section{Research}

In 1999 the National Board of Examiners requested that all residents submit research reports with their application for the national examination.

\section{Examinations}

At the end of each year (in some institutes twice a year, midyear as well as end of year), each institute sets examinations. There are three sections: a written paper, a case interview and an oral examination. The written paper consists of three parts: 150 multiple-choice questions, sat in 3.5 hours; six modified essay questions (MEQs), sat in 3 hours; and six short essays, sat in 3 hours (five of these relate to psychiatry and one to neurology). The pass mark is $50 \%$.

For the case examination, trainees have to interview two psychiatric patients and evaluate one neurological case. They have 30 minutes to interview each patient and 45 minutes to summarise and answer questions. The pass mark is $60 \%$ for each case; marks are awarded by two independent examiners.

For their oral examination, trainees are assessed in 1 hour by three examiners in the following areas: knowledge, attitude towards the profession, cultural considerations, ethics, judgement and emergency decision-making skills. The examiners grade each area $A, B, C$ or $F$. Examinees will pass if they do not receive any Fs.

If trainees fail a case examination only, they will have a chance to resit within the following 6 months, but if they fail in written and case examinations they will have to resit the next year. After the examination, trainees are asked to provide feedback on the examination process to the National Board of Examiners.

Trainees who pass the National Board examination are qualified to apply to be Fellows of the Royal College of Psychiatrists of Thailand (RCPsychT). When their application has been approved by the executive committee of the College, they can use the letters FRCPsychT after their family names. As of 8 February 2007 there were only 407 Fellows.

\section{Conclusion}

Psychiatric residency training in Thailand is at present offered for only general and child and adolescent psychiatry. Training in other sub-specialties, such as geriatric psychiatry or forensic psychiatry, is not yet available. The number of doctors who apply for training in psychiatry is increasing, which means a bright future for teaching and training in Thailand can be expected.

\section{Further reading}

Udomratn, P. (2003) Psychiatric education in Thailand. ASEAN Journal of Psychiatry, 6, 102-106.

\title{
Self-harm by poisoning in Mauritius
}

\section{Mridula S. Naga, MBBS MRCPsych DPM(Lond)}

Senior Psychiatrist, Victoria Hospital, Mauritius, email drmridunaga@hotmail.com

\begin{abstract}
uicide rates and rates of self-harm are high in Mauritius.
This report concerns a comprehensive analysis of the incidence of self-poisoning on the island. The incidence of self-poisoning could be minimised if all the causative factors contributing to the practice were identified. Since this form of self-harm is influenced by demographic patterns, the social and economic environment, legal provisions and the healthcare system, a study specific to Mauritius will be of great relevance.

Self-harm is defined as a non-fatal act in which an individual deliberately caused self-injury or ingested a substance in excess of any prescribed or generally recognised dosage (Kreitman, 1977). The term self-poisoning is used when the
\end{abstract}

self-harm results from drug overdose or ingestion of other noxious agents and where there is no intention to die.

\section{Background}

The Republic of Mauritius is a group of islands in the southwest of the Indian Ocean, east of Madagascar, with a population of about 1.2 million. The population is multiracial and multi-ethnic, with origins from the continents of Asia, Africa and Europe: $68 \%$ of the population are IndoMauritians, 27\% are Creoles, 3\% are Sino-Mauritians and 2\% are Franco-Mauritians. Around $24 \%$ of the population are 
under the age of 14 years, $70 \%$ between the ages of 15 and 64 and $7 \%$ over 65 years. Forty-eight per cent of the population is Hindu, 32\% Christian and 17\% Muslim.

Mauritius is classified as an upper-middle-income country in sub-Saharan Africa by the World Bank. Its per capita gross domestic product is US\$13200. Mauritian society has undergone a process of rapid economic and social change and modernisation over the past three decades. With the advent of tourism as an industry, better air services and the electronic media, Mauritius has opened up to the rest of the world. The birth rate has dropped to 15.3 per 1000 population and a typical family has two or three children. Life expectancy is 68.6 years for males and 76.6 years for females. The literacy rate is $86 \%$. Primary education has been compulsory for many years and secondary education is so now. There is gender equality as far as education is concerned. The increasing numbers of school-leavers have led to an imbalance between opportunities and aspirations, which has caused some frustration and maladjustment. With the establishment of an 'export processing zone', many literate women in the country have found employment. This has also contributed to a change in the fabric of society.

The Ministry of Health is the governing body responsible for providing health services. Mental health services have been decentralised; units in all regional hospitals provide outpatient care as well as liaison psychiatric services.

\section{Self-poisoning: a survey}

Self-harm is the strongest risk factor for suicide (Owens et al, 2002). According to government (in-patient) statistics there was a sudden rise in attempted suicide in 1998, to 118 per 100000 , followed by a gradual decline, to 78 per 100000 in 2004 (Fig. 1).

For the present study, 147 patients admitted as a result of self-poisoning to a regional general hospital in an urban area between August 2004 and July 2005 and referred to the psychiatric unit were reviewed. They constituted about $30 \%$ of the total in-patient referrals. During the same period 28 patients claimed to have ingested poisonous substances accidentally.

There are no rules or regulations regarding referral of such patients - the physicians refer at their own discretion;

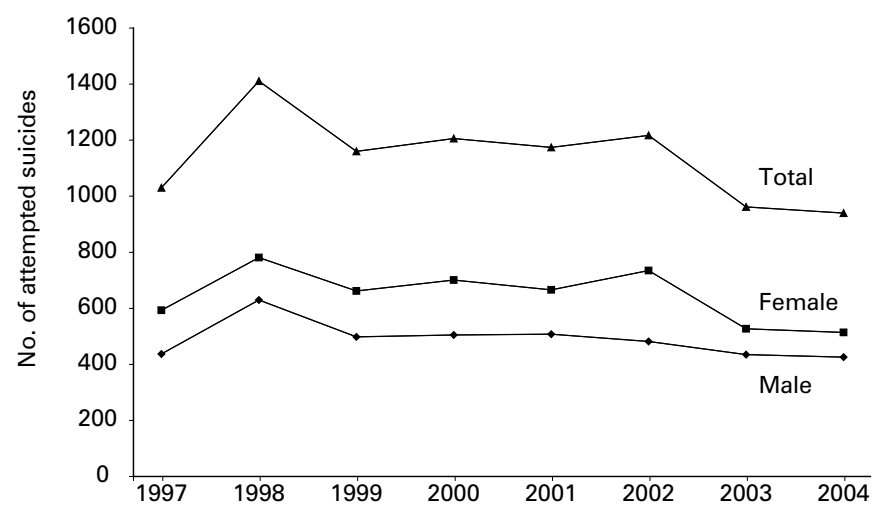

Figure 1 Number of suicide attempts in Mauritius (public sector in-patients statistics), 1997-2004.

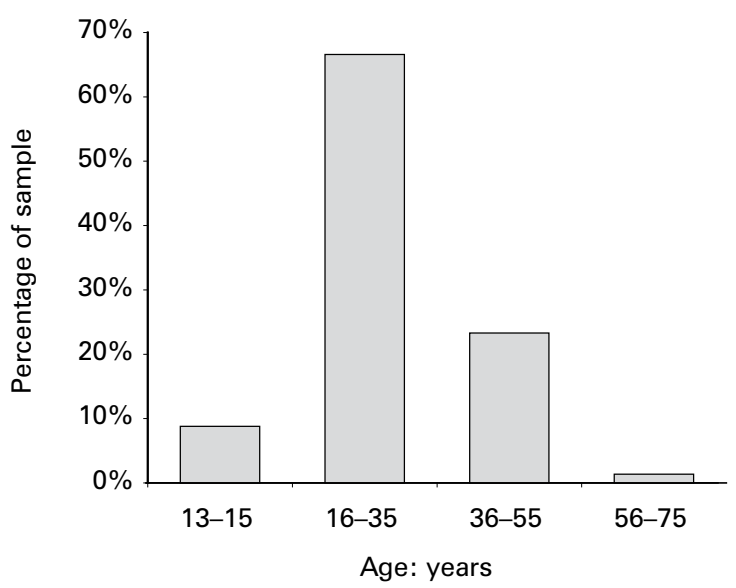

Figure 2 Age distribution of study sample (all cases of selfpoisoning admitted to a regional general hospital in an urban area between August 2004 and July 2005, $n=147$ ).

however, the majority of such patients are referred to the psychiatrist.

A slight majority of the 147 patients reviewed were female (58.5\%; male:female ratio of 1:1.4). More males (64\%) than females (55\%) were single. Although single, most of them were living with family.

Figure 2 shows the age distribution of the sample. The majority (67\%) of patients were between the ages of 16 and 35 years; $23 \%$ were between 36 and 55 years. That $9 \%$ were in the age group 13-15 years is of some concern. Only $1 \%$ of the sample was over the age of 55 .

The difference between religious groups was striking: $57 \%$ of the sample were Hindu and 13\% Muslim, with Christians (Catholics) comprising the other 30\%. However, if the absolute percentages are normalised to the religious make-up of the general population then the difference is less marked.

Forty-five per cent of the patients had education up to upper secondary level, similar to the findings of another study of attempted suicide carried out in Mauritius (Dewkurrun, 2002). Eighteen per cent had been educated up to lower secondary level and 35\% had had only primary-school education. The level of education was higher for females than for males.

The incidence of past psychiatric illness was higher than reported by Dewkurrun (2002). Ten per cent of the sample had made a previous attempt at self-poisoning, females more than males.

Twenty per cent had imbibed alcohol before the act of self-poisoning; most of these were male (71\%). In these instances alcohol was found to be the disinhibiting factor or they had had disputes because of the drinking. Ten per cent of the patients were diagnosed with alcohol dependence syndrome. Chronic alcohol and drug problems have been cited as a risk factor for self-harm and eventual suicide (Beck \& Steer, 1989). The incidence of past medical illness was not significant (5\%).

Figure 3 shows the agents used by the sample. Selfpoisoning took the form of an overdose of a medicine in $60 \%$. In 22\% psychotropic drugs were used. Paracetamol, either prescribed or bought over the counter, was used in 


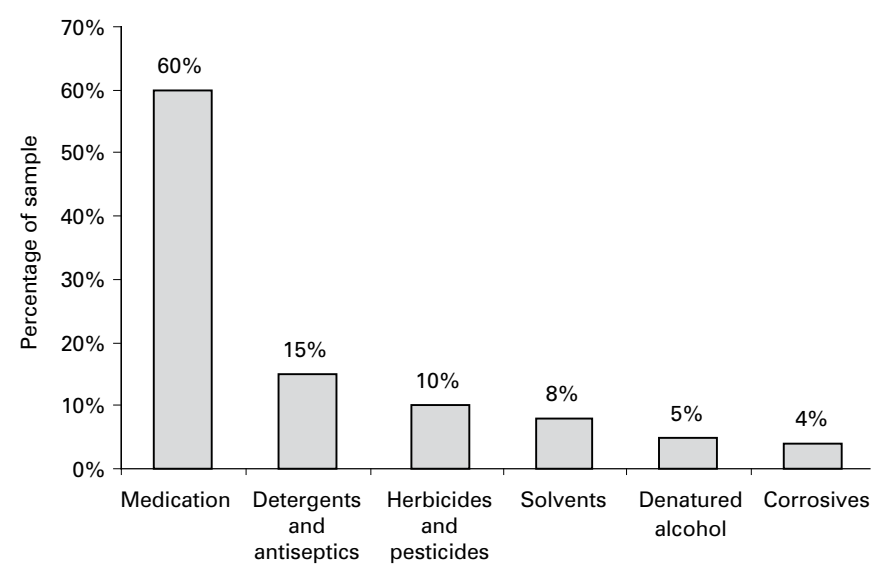

Figure 3 Agents used for self-poisoning $(n=147)$.

14\%. Other prescribed drugs were commonly used (24\%); these included chlorphenamine, ibuprofen and antibiotics. In some instances a mixture of alcohol and paracetamol or other tablets was used. Detergents and antiseptics (which are readily available) were used by $15 \%$. Herbicides or pesticides were used by only $10 \%$. Solvents were used in $8 \%$ and corrosives in $4 \%$ of cases, with serious consequences. Denatured alcohol (commonly for cleaning purposes) was used in $5 \%$ of cases.

Most of the acts were impulsive, in response to social problems. The reasons for self-poisoning varied. Interpersonal difficulties were common, and often involved a spouse (26\%) or another family member (24\%). Alcohol misuse was an important factor. Other reasons cited were disputes with a boyfriend or girlfriend, problems with parents (especially among the young), unsatisfactory academic results and financial problems.

Major medical complications were mostly seen in cases of corrosive poisoning. Minor complications like gastric irritation were common.

\section{Discussion}

According to government statistics, the number of people attempting suicide seems to be diminishing. It is worth mentioning that these statistics are wholly based on inpatient admissions to government hospitals; those admitted to private clinics are not included. Further, many people who do not become seriously ill as a consequence of selfpoisoning do not come forward for treatment, but instead resort to home remedies. Attempted suicide is not an offence in Mauritius, but social prejudice following self-harm is so strong that many people try to conceal it.

The large number of young people seen is in keeping with studies carried out locally and worldwide. The transition from a traditional to a modern society typically generates conflicts between the younger generation and their parents. In this group a large percentage had received secondary education and might have been frustrated by unsatisfied aspirations. The stress associated with work and family responsibilities for literate married women who had entered the labour force was also noted, as were the difficulties faced by the spouse.
In the married group social problems resulting from alcohol misuse were common. The difference in incidence among the three principal religious groups was significant; a similar finding was reported from Fiji, which has an immigrant population similar to that of Mauritius (Haynes, 1984).

The means used for self-poisoning has changed over the years. Prescribed psychotropic and other drugs have become more readily available. The free sale of highly toxic herbicides and pesticides has been curtailed and this has had a positive effect.

Although the numbers of patients with psychiatric illnesses were relatively high, these were impulsive acts without suicidal intent. However, proper assessment of this group is of great importance. Social factors were contributory, most probably having led to the illness in the first place.

\section{Conclusion}

These findings have implications for suicide prevention strategies:

The young population has to be targeted. The introduction of education on mental health in secondary schools will be of prime importance and will not be too difficult to implement. Regular counselling and education sessions on suicide and self-harm and related topics will have to be organised at youth centres (these are present in all regions of the island).

O A protocol for assessing patients attending casualty after an act of self-harm has to be established, so that they are seen by trained personal and further assistance and follow-up are given. These patients are more likely to die by suicide. As many fail to attend follow-up clinics, support and counselling services away from hospital would probably be more effective.

O In addition to the National Strategic Action Plan for Suicide Prevention which was implemented in 2006, the introduction of a national policy to deal with alcohol dependence and related problems will be of great preventive value.

O Community psychiatric services and social workers can also aid the prevention of suicide.

o Non-governmental organisations are active in this sector and their contribution should be recognised and encouraged.

O Enlisting the services of sociocultural organisations to educate the vulnerable population will also have to be considered.

\section{References}

Beck, A. T. \& Steer, R. A. (1989) Clinical predictors of eventual suicide: a 5 - to 10-year prospective study of suicide attempters. Journal of Affective Disorders, 17, 203-209.

Dewkurrun, G. (2002) Attempted Suicide in Mauritius: A Sociological Study. Dissertation thesis, University of Mauritius.

Haynes, R. H. (1984) Suicide in Fiji: a preliminary study. British Journal of Psychiatry, 145, 433-438.

Kreitman, N. (ed.) (1977) Parasuicide. Wiley.

Owens, D., Horrocks, J. \& House, A. (2002) Fatal and non-fatal repetition of self-harm. Systematic review. British Journal of Psychiatry, 181, 193-199. 